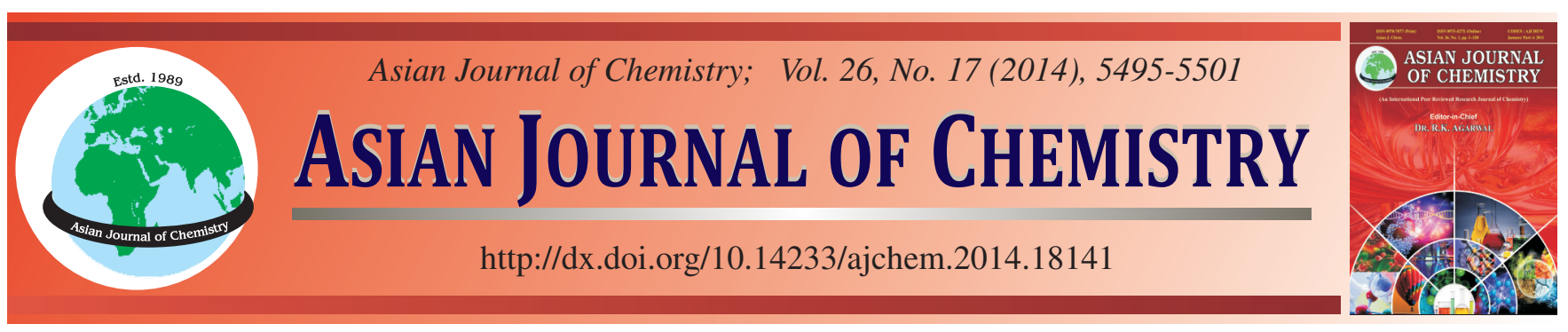

\title{
Analytical Solutions of Dynamic Extension Problem of Mode III Semi-Infinite Crack Subjected to Moving Increasing Loads $\dagger$
}

\author{
Nian-Chun Lü ${ }^{1, *}$, Qian XIAng ${ }^{1}$ and Guo-Dong HaO ${ }^{2}$
}

${ }^{1}$ School of Material Engineering, Shenyang Ligong University, Shenyang 110168, P.R. China

${ }^{2}$ Department of Chemistry, Mudanjiang Normal College, Mudanjiang 157001, P.R. China

*Corresponding author: E-mail: lnc_65@163.com

Dynamic extension problem of mode III semi-infinite crack was investigated by means of the theory of complex variable functions, which can be facilely transformed into Riemann-Hilbert problems. Analytical solutions of stress, displacement and stress intensity factor under the conditions of moving increasing loads $\mathrm{Px}^{2} / \mathrm{t}^{2}$ and $\mathrm{Pt}^{3} / \mathrm{x}^{2}$, respectively, are very easily obtained using the ways of self-similar functions.

Keywords: Complex functions, Dynamic propagation problems, Mode III semi-infinite crack, Self-similar functions, Analytical solutions.

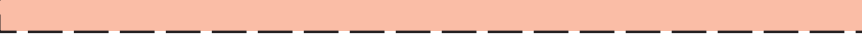

\section{INTRODUCTION}

Statics problems of antiplane shear loading were studied in the past of several decades ${ }^{1-3}$. Dynamic problem is an important research field in modern fracture mechanics. Due to the interaction of the stress waves under complex dynamic loading cases, the theory of dynamic fracture mechanics is still innovated and developed ${ }^{4}$. However, many engineering structures are under the conditions of dynamic loadings and the static theory cannot effectually resolve a series of dynamic queries, so it is indispensable to study the fracture dynamics problems ${ }^{5-8}$. In view of the complexity in mathematics for dynamic fracture of the edge crack and nonhomogeneous propagation crack problems, both numerical solutions and half analytical solutions are obtained by those literatures ${ }^{9-13}$, moreover analytical solutions are obtained much less ${ }^{14-16}$. Therefore, it is necessary to study active propagation problem concerning mode III semiinfinite crack. Universal expressions of solutions are given by means of the theory of complex functions in this paper. The problems studied can be easily transformed into a RiemannHilbert problem using Muskhelishvili's method ${ }^{17,18}$. The objective of this paper is to show obtaining expediently analytical solutions through the self-similar functions under the action of moving increasing loads.

\section{EXPERIMENTAL}

Correlative equations of antiplane problem concerning elastodynamics for an orthotropic anisotropic body: For an orthotropic anisotropic body, let the Cartesian co-ordinates be coincident with the axes of elastic symmetry. The problems considered are confined in the antiplane. The antiplane equation of motion for an orthotropic anisotropic body is given by $^{1-4,6,7}$ :

$$
\frac{\mathrm{C}_{55} \partial^{2} \mathrm{w}}{\partial \mathrm{x}^{2}}+\frac{\mathrm{C}_{44} \partial^{2} \mathrm{w}}{\partial \mathrm{y}^{2}}=\frac{\rho \partial^{2} \mathrm{w}}{\partial \mathrm{t}^{2}}
$$

where $\mathrm{C}_{44}, \mathrm{C}_{55}$ are the elastic constants, $\rho$ is the mass density and $\mathrm{w}$ is the displacement component $\mathrm{t}^{4-7,15,16,19,20}$ along $\mathrm{Z}$.

Using Atkinson transform [19-20, 15-16 ], it is found that

$$
\xi=\mathrm{x}-\eta \mathrm{t}+\mathrm{Ty}
$$

where $\eta$ is to be understood as a complex variable and $T$ is a function of $\eta$.

A solution of equation of motion can be written as:

$$
\mathrm{w}=\operatorname{Re}\left[\int_{-\infty}^{\infty} \phi(\xi) \mathrm{d} \eta\right]
$$

where the integral is the real part of $\eta$-axis.

Now putting eqn. 3 into 1 , the following representation must exist:

$$
\mathrm{C}_{55}+\mathrm{C}_{44} \mathrm{~T}^{2}-\rho \eta^{2}=0
$$

Eqn. 1 will become identical equation, hence $\phi(\xi)$ is a discretionary function to be determined from the boundary conditions. 
Postulating that eqn. 4 has two complex roots, then we only take the imaginary part with the positive sign, i.e., positive square root. Here exists ${ }^{4,15,16,19,20}$ :

$$
\mathrm{T}(\eta)=\mathrm{i} \sqrt{\left(\mathrm{C}_{55}-\rho \eta^{2}\right) / \mathrm{C}_{44}}
$$

At $y=0$, one attains the universal conclusions ${ }^{4,15,16,19}$ :

When functions Lw is homogeneous, there results

$$
\mathrm{w}^{0}=\mathrm{Lw}, \tau_{\mathrm{xz}}{ }^{0}=\mathrm{L} \tau_{\mathrm{xz}}, \tau_{\mathrm{yz}}{ }^{0}=\mathrm{L} \tau_{\mathrm{yz}}
$$

When $L \tau_{\mathrm{xz}}$ and $L \tau_{\mathrm{yz}}$ are homogeneous, there results

$$
\mathrm{w}^{0}=\frac{\partial \mathrm{Lw}}{\partial \mathrm{t}}, \tau_{\mathrm{xz}}{ }^{0}=\frac{\partial \mathrm{L} \tau_{\mathrm{xz}}}{\partial \mathrm{t}}, \tau_{\mathrm{yz}}{ }^{0}=\frac{\partial \mathrm{L} \tau_{\mathrm{yz}}}{\partial \mathrm{t}}
$$

where: $L=\frac{\partial^{m+n}}{\partial x^{m} \partial t^{n}}$, inverse: $L^{-}=\frac{\partial^{-m-n}}{\partial x^{-m} \partial t^{-n}}$. Here $+m+$ $\mathrm{n},-\mathrm{m}-\mathrm{n}$ and 0 represent the $(\mathrm{m}+\mathrm{n})$ th order derivative, the $(\mathrm{m}+\mathrm{n})$ th order integral and function's self, respectively. The coefficients $\mathrm{m}, \mathrm{n}$ will be called the indices of self-similarity ${ }^{4}$, $15,16,19,20$

With the help of the notation introduced, all the general expressions can be rewritten in the following format:

$$
\begin{gathered}
\tau_{\mathrm{yz}}{ }^{0}=\frac{1}{\mathrm{t}} \operatorname{Re}[\mathrm{f}(\tau) \mathrm{T}(\tau)], \\
\tau_{\mathrm{xz}}{ }^{0}=\frac{\mathrm{C}_{55}}{\mathrm{C}_{44} \mathrm{t}} \operatorname{Ref}(\tau) \\
\frac{\partial \mathrm{w}^{0}}{\partial \tau}=\frac{1}{\mathrm{C}_{44}} \operatorname{Ref}(\tau)
\end{gathered}
$$

where: $\tau=\mathrm{x} / \mathrm{t}, \mathrm{f}(\tau)$ is self-similar functions. The values of $\mathrm{T}(\tau)$ can be ascertained from eqn. 5 . Indicated that $T(\tau)$ in the area of the subsonic speeds is purely imaginary for the considered values. Thus, elastodynamics problems for an orthotropic anisotropic body can be translated into the sole unknown function problems of $f(\tau)$ meeting the boundary-value conditions. In the general case, this is Riemann-Hilbert problem in the theory of complex functions for the simplest case, which is the Keldysh-Sedov or Dirichlet problem ${ }^{17,18}$.

Dynamic semi-infinite crack propagation of orthotropic solids under antiplane shear loading: Assume at the initial moment $\mathrm{t}=0$, a crack begins to nucleate from an infinitesimally small micro-crack under the action of shear loads $\mathrm{P}$ located at the point of infinity, propagating with constant velocity $\mathrm{V}$ (for the subsonic speeds) in the positive direction of $\mathrm{x}$-axis. The schematic of dynamic semi-infinite crack extension of orthotropic solids under anti-plane shear loading is indicated in Fig. 1. The contour is symmetry both in geometry and mechanics with respect to $\mathrm{x}$-axis, but it is the asymmetry with respect to y-axis in virtue of crack semiinfinite extension. The crack located in the zone of $y=0,0$ $<\mathrm{x}<\mathrm{Vt}$; moreover closed force $\mathrm{P}$ acts on this segment, whose magnitude is unknown, unascertained. The strength denotes shear stress $\tau$ lying in the rear segment of the crack tip. When the crack runs at high speed, its dimension must relate to variables $\mathrm{x}$ and $\mathrm{t}$, then the crack edges subjected to loads also have relation to variables $\mathrm{x}$ and $\mathrm{t}$.

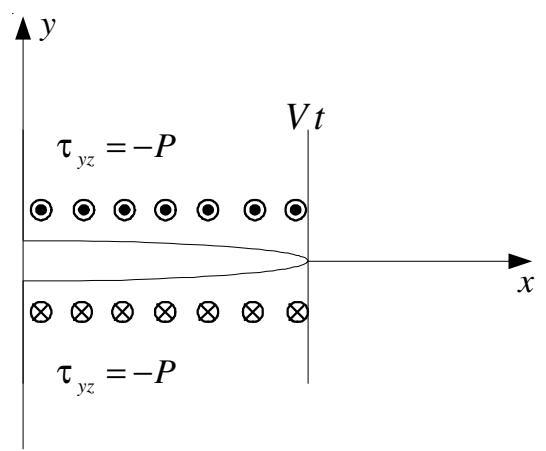

Fig. 1. Schematic diagram of dynamic semi-infinite crack extension of orthotropic solids under antiplane shear loading

Rudimental solution of dynamic extension for semiinfinite crack problem: Postulated at the initial moment $\mathrm{t}=$ 0 , a micro-crack suddenly occurs at an orthotropic anisotropic body, the Cartesian co-ordinate axes are presented which accords with the axes of elastic symmetry of the body and the motion of the crack is restricted in the $x-y-p l a n e$ at constant velocity $\mathrm{V}$ in the positive direction of $\mathrm{x}$-axis. The correlative following boundary will be depicted as:

$$
\tau_{\mathrm{yz}}(\mathrm{x}, 0, \mathrm{t})=\mathrm{g}_{1}(\mathrm{x}, \mathrm{t}), 0<\mathrm{x}<\mathrm{Vt} ; \mathrm{w}(\mathrm{x}, 0, \mathrm{t})=0, \mathrm{x}>\mathrm{Vt}
$$

Introducing the variable $\tau=\mathrm{x} / \mathrm{t}$. In terms of eqn. 8 and $\mathrm{t} \delta(\mathrm{x})=\delta(\mathrm{x} / \mathrm{t})$ in the theory of generalized functions $\mathrm{s}^{21-23}$, the mentioned-above boundary conditions can be translated into the undermentioned boundary value queries:

$$
\begin{gathered}
\operatorname{Re}[\mathrm{f}(\tau) \mathrm{T}(\tau)]=\mathrm{g}_{2}[\tau, \delta(\tau)] \\
0<\tau<\mathrm{V} ; \operatorname{Re} \mathrm{f}(\tau)=0, \tau>\mathrm{V}
\end{gathered}
$$

In terms of eqn. 8 and the previous conditions, the unique unbeknown function $f(\tau)$ must have the form:

$$
\mathrm{f}(\tau)=\mathrm{g}_{3}[(\tau, \xi(\tau)]
$$

Then the problem considered can became down to Keldysh-Sedov problem:

$$
\operatorname{Re} \mathrm{m}(\tau)=0, \tau>\mathrm{V} ; \operatorname{Im} \mathrm{m}(\tau)=0,0<\tau<\mathrm{V}
$$

Considering synthetically dissymmetry and the conditions of the infinite point of the plane corresponding to the origin of coordinates of the physical plane as well as singularities of the stress at the crack tip ${ }^{23-25}$ the rudimental solution of the above problems can be obtained as follows:

$$
\xi(\tau)=\mathrm{g}_{4}[(\mathrm{~V}-\tau), \tau]
$$

Afterwards applying eqns. 8 and 5 , the stress, the displacement and the stress intensity factor under the conditions of semi-infinite crack expansion problem will be easily derived.

Solutions of frondose problems: In order to resolve effectually fracture dynamics problems on an orthotropic anisotropic body, solutions will be obtained under the action of variable loads for mode III semi-infinite crack. In terms of the principle of generalized functions, the unlike boundary condition problems will be changed into Keldysh-Sedov mixed boundary value problem using the measure of self-similar functions and the corresponding solutions will be obtained.

Presumed at the initial moment $\mathrm{t}=0$, a micro-crack is abruptly initiated and begins to move at constant velocity $\mathrm{V}$ along the positive direction of $\mathrm{x}$-axis. The crack surfaces are subjected to standard point force $\mathrm{Px}^{2} / \mathrm{t}^{2}$, moving at a constant 
velocity $\beta<\mathrm{V}$ along the positive direction of $\mathrm{x}$-axis. On the half-plane at $y=0$, the boundary conditions will be shown as follows:

$$
\begin{gathered}
\tau_{\mathrm{yz}}(\mathrm{x}, 0, \mathrm{t})=-\frac{\mathrm{Px}^{2}}{\mathrm{t}^{2}} \cdot \delta(\mathrm{x}-\beta \mathrm{t}) \\
0<\mathrm{x}<\mathrm{Vt}, \mathrm{w}(\mathrm{x}, 0, \mathrm{t})=0, \mathrm{x}>\mathrm{Vt}
\end{gathered}
$$

Evidently the displacement will be homogeneous functions, in which. Using $\tau=\mathrm{x} / \mathrm{t}$ and the theory of generalized functions $^{24,25}$ as well as eqns. 8 and 6 , the first of eqn. 14 can be rewritten:

$$
\begin{gathered}
\operatorname{Re}[\mathrm{T}(\tau) \mathrm{f}(\tau)]=-\frac{\mathrm{Px}^{2}}{\mathrm{t}^{2}} \mathrm{t} \delta(\mathrm{x}-\beta \mathrm{t})=-\mathrm{P} \tau^{2} . \delta(\tau-\beta) ; \\
0<\tau<\mathrm{V}
\end{gathered}
$$

Deducting from the above formulae, the unique solution of $f(\tau)$ must have this form:

$$
f(\tau)=\frac{\tau^{2} \cdot \xi(\tau)}{(\tau-\beta)}
$$

In the formula $\xi(\tau)$ has no singularity in the domain of 0 $<\tau<\mathrm{V}$, while $\mathrm{T}(\tau)$ is purely imaginary for the subsonic speeds; hence $\xi(\tau)$ must be purely real in the section of $0<\tau<\mathrm{V}$. Thus, eqn. 16 becomes:

$$
\operatorname{Re} \mathrm{m}(\tau)=0, \tau>\mathrm{V} ; \operatorname{Im} \mathrm{m}(\tau)=0,0<\tau<\mathrm{V}
$$

In terms of dissymmetry and the conditions of the infinite point of the plane corresponding to the origin of coordinates of the physical plane as well as singularities of the crack tip ${ }^{23,25}$ the unique solution of the Keldysh-Sedov problem 17 can be obtained:

$$
\xi(\tau)=\frac{\mathrm{A}}{\sqrt{(\mathrm{V}-\tau) \tau}}
$$

where, $\mathrm{A}$ is an unknown constant.

Putting eqn. 18 into 16, one can gain:

$$
f(\tau)=\frac{A \tau^{2}}{[(\tau-\beta) \sqrt{(V-\tau) \tau}]}
$$

Substituting eqn. 19 into eqns. 15 and 5 , at $\tau \rightarrow \beta$, constant A will be ascertained:

$$
A=-\frac{P \sqrt{(V-\beta) \beta}}{\left[\pi \sqrt{\frac{\left(C_{55}-\rho \beta^{2}\right)}{C_{44}}}\right]}
$$

Afterwards eqns. 19 and 5 may be replaced into eqns. 6 and 8 , at the surface $\mathrm{y}=0$, the stress $\tau_{\mathrm{yz}}$, the displacement $\mathrm{w}$ and dynamic stress intensity factor $\mathrm{K}_{3}(\mathrm{t})$ are obtained, respectively:

$$
\begin{aligned}
\tau_{\mathrm{yz}}=\tau_{\mathrm{yz}}^{0} & =\frac{1}{\mathrm{t}} \operatorname{Re}[\mathrm{f}(\tau) \mathrm{T}(\tau)]=\frac{1}{\mathrm{t}} \cdot \operatorname{Re} \frac{\mathrm{A} \cdot \tau^{2} \cdot \mathrm{T}(\tau)}{(\tau-\beta) \sqrt{(\tau-\mathrm{V}) \tau}} \\
= & \frac{\mathrm{A} \tau^{2} \sqrt{\left(\mathrm{C}_{55}-\rho \tau^{2}\right) / \mathrm{C}_{44}}}{(\tau-\beta) \sqrt{(\mathrm{x}-\mathrm{Vt}) \mathrm{x}}}, \mathrm{x}>\mathrm{Vt}
\end{aligned}
$$

$$
\begin{gathered}
\mathrm{w}=\mathrm{w}^{0}=\frac{1}{\mathrm{C}_{44}} \operatorname{Re} \int_{\propto}^{\mathrm{x} / \mathrm{t}} \frac{\mathrm{A} \tau^{2}}{(\tau-\beta) \sqrt{(\mathrm{V}-\tau) \tau}} \mathrm{d} \tau \\
=\frac{\mathrm{A}}{\mathrm{C}_{44}} \cdot\left\{(\mathrm{V}+2 \beta) \cdot \arcsin \sqrt{\frac{\mathrm{x}}{\mathrm{Vt}}}-\frac{1}{\mathrm{t}} \sqrt{(\mathrm{Vt}-\mathrm{x}) \mathrm{x}}\right. \\
\left.+\frac{\beta^{2}}{\sqrt{1}} \ln \left|\frac{-\sqrt{(\mathrm{Vt}-\mathrm{x}) \mathrm{x}}+\mathrm{t} \sqrt{1}}{\mathrm{x}-\beta \mathrm{t}}+\frac{\mathrm{V}+2 \beta}{2 \sqrt{1}}\right|\right\}, 0<\mathrm{x}<\mathrm{Vt}
\end{gathered}
$$

where: $1=\mathrm{V} \beta-\beta^{2}$. Its result is acquired by application of formulas in the literature ${ }^{26}$.

$$
\begin{gathered}
K_{3}(t)=\lim _{x \rightarrow V t} \sqrt{2 \pi(x-V t)} \cdot \frac{A \tau^{2} \sqrt{\left(C_{55}-\rho \tau^{2}\right) / C_{44}}}{(\tau-\beta) \sqrt{(x-V t) x}} \\
=\frac{A V^{3 / 2} \sqrt{2 \pi\left(C_{55}-\rho V^{2}\right) / C_{44}}}{(V-\beta) \sqrt{t}}
\end{gathered}
$$

Known from eqn. 23, dynamic stress intensity factor $\mathrm{K}_{3}(\mathrm{t})$ decays slowly and has an obvious singularity owing to only one variable $t$ in the denominator and the rest units are all real constants.

With all conditions holding the same as that discussed in the previous example, the loads become $\mathrm{Pt}^{3} / \mathrm{x}^{2}$. The boundary conditions will be as follows:

$$
\begin{gathered}
\mathrm{f}(\tau)=\mathrm{A} /\left\{\tau^{2}(\tau-\beta)[(\mathrm{V}-\tau) \tau]^{3 / 2}\right\} \\
0<\tau<\mathrm{V} ; \mathrm{w}(\mathrm{x}, 0, \mathrm{t})=0, \mathrm{x}>\mathrm{Vt}
\end{gathered}
$$

Apparently the stress will be homogeneous functions in which $\mathrm{L}=1$. According to eqns. 7 and 8 as well as the theory of generalized functions ${ }^{21-23}$, the first of eqn. 24 can be rewritten as:

$$
\begin{gathered}
\operatorname{Re}[\mathrm{T}(\tau) \mathrm{f}(\tau)]=-\frac{3 \mathrm{Pt}^{2}}{\mathrm{x}^{2}} \cdot \mathrm{t} \delta(\mathrm{x}-\beta \mathrm{t})=-3 \mathrm{P} \tau^{-2} \delta(\tau-\beta) \\
0<\tau<\mathrm{V}
\end{gathered}
$$

At $x \neq \beta$ t, the derivative of $t \delta(x-\beta t)$ is zero, therefore the result will be obtained.

Deducting from the above formulae, the sole solution of $\mathrm{f}(\tau)$ must have this form:

$$
f(\tau)=\frac{\xi(\tau)}{\left[\tau^{2}(\tau-\beta)\right]}
$$

In the formula $\xi(\tau)$ has no singularity in the domain of 0 $<\tau<\mathrm{V}$, while $\mathrm{T}(\tau)$ is purely imaginary for the subsonic speeds; hence $\xi(\tau)$ must be purely real in the section of .Thus, eqn. 25 nduces:

$\operatorname{Re} \mathrm{m}(\tau)=0, \tau>\mathrm{V} ; \operatorname{Im} \mathrm{m}(\tau)=0,0<\tau<\mathrm{V}$

In terms of asymmetry and the conditions of the infinite point of the plane corresponding to the origin of coordinates of the physical plane as well as singularities of the crack tip ${ }^{23-}$ ${ }^{25}$ the unique solution of the Keldysh-Sedov problem 27 can be obtained:

$$
\xi(\tau)=\frac{\mathrm{A}}{[(\mathrm{V}-\tau) \tau]^{3 / 2}}
$$


where, A is an unbeknown constant.

Replacing eqn. 28 into 26, we can gain:

$$
f(\tau)=\frac{A}{\left\{\tau^{2}(\tau-\beta)[(V-\tau) \tau]^{3 / 2}\right\}}
$$

Putting eqn. 29 into 26, 5, at $\tau \rightarrow \beta$, constant A will be ascertained:

$$
A=-\frac{3 P[(V-\beta) \beta]^{3 / 2}}{\left\{\pi \sqrt{\left(C_{55}-\rho \beta^{2}\right) / C_{44}}\right\}}
$$

In an orthotropic isotropic body, the disturbance range of elastic wave can be denoted by the circular region of radius $c_{1} t$ and $c_{2} t$, here $c_{1}$ and $c_{2}$ are the velocities of longitudinal and transverse waves $\left(c_{1}>c_{2}\right)$ of the elastic body respectively. In an orthotropic anisotropic body, the disturbance range of elastic wave is not the circular area and can not exceed the threshold value $\mathrm{C}_{\mathrm{d}}=\sqrt{\mathrm{C}_{55} / \rho}$ (sonic velocity) of the elastic body. At $|\mathrm{x}|>\mathrm{C}_{\mathrm{d}} \mathrm{t}$, with $\operatorname{Im}[\mathrm{T}(\tau)]=0$, thus the stresses and the displacements are zero, which coincide with the initial conditions; and this narrates that at the surface $y=0$, the disturbance of elastic wave can not exceed $\mathrm{C}_{\mathrm{d}} \mathrm{t}$.

Then putting eqns. 29 and 5 into eqns. 7 and 8 , at the surface $\tau_{\mathrm{yz}}$, the displacement $\mathrm{w}$ and dynamic stress intensity factor $\mathrm{K}_{3}(\mathrm{t})$ are obtained, respectively:

$$
\begin{gathered}
\tau_{\mathrm{yz}}=\int_{\infty}^{\mathrm{x}} \frac{1}{\mathrm{t}} \operatorname{Re} \frac{\mathrm{A} \sqrt{\left(\mathrm{C}_{55}-\rho \tau^{2}\right) / \mathrm{C}_{44}}}{\tau^{2}(\tau-\beta)[(\mathrm{V}-\tau) \tau]^{3 / 2}} \mathrm{dt} \\
=-\operatorname{Re} \int_{\mathrm{C}_{\mathrm{d}}}^{\frac{\mathrm{x}}{\mathrm{t}}} \frac{\mathrm{A} \sqrt{\left(\mathrm{C}_{55}-\rho \tau^{2}\right) / \mathrm{C}_{44}}}{\tau^{3}(\tau-\beta)[(\tau-\mathrm{V}) \tau]^{3 / 2}} \mathrm{~d} \tau, \mathrm{x}>\mathrm{Vt}
\end{gathered}
$$

$$
\begin{aligned}
\mathrm{K}_{3}(\mathrm{t})=\lim _{\mathrm{x} \rightarrow \mathrm{V}_{1} \mathrm{t}} \sqrt{2 \pi(\mathrm{x}-\mathrm{Vt})} \cdot \operatorname{Re} \int_{\mathrm{C}_{\mathrm{d}}}^{\frac{\mathrm{x}}{\mathrm{t}}}-\frac{\mathrm{A} \sqrt{\left(\mathrm{C}_{55}-\rho \tau^{2}\right) / \mathrm{C}_{44}}}{\tau^{3}(\tau-\beta)[(\tau-\mathrm{V}) \tau]^{3 / 2}} \mathrm{~d} \tau \\
=2 \sqrt{2 \pi \mathrm{t}} \cdot \frac{\mathrm{A} \sqrt{\left(\mathrm{C}_{55}-\rho \mathrm{V}^{2}\right) / \mathrm{C}_{44}}}{(\mathrm{~V}-\beta) \mathrm{V}^{9 / 2}}
\end{aligned}
$$

The limit of the above formula remains with the shape of $0^{\prime} \infty$, which should be translated into the type of $\infty / \infty$, then its result can be computed by means of L'Hospital theorem ${ }^{27}$.

In order to represent expediently, eqn. 29 can be rewritten as:

$$
\begin{gathered}
f(\tau)=\frac{A}{\tau^{2}(\tau-\beta)[(V-\tau) \tau]^{3 / 2}} \\
=\frac{1}{\beta}\left[-\frac{1}{\tau \beta}+\frac{1}{(\tau-\beta) \beta}-\frac{1}{\tau^{2}}\right] \frac{A}{[(V-\tau) \tau]^{3 / 2}}
\end{gathered}
$$

For the sake of conveniency, it is assumed that:

$$
\mathrm{X}=(\mathrm{V}-\tau) \tau=\mathrm{V} \tau-\tau^{2}
$$

Based on the above results, its relative constants can be represented as: $\mathrm{a}=0, \mathrm{~b}=\mathrm{V}, \mathrm{c}=-1, \mathrm{~K}=4 \mathrm{ac}-\mathrm{b}^{2}=\mathrm{V}^{2}$. $\mathrm{w}^{0}$.

Integrating eqn. 33 , in the light of eqn. 8 , one will obtain

$$
\begin{aligned}
\mathrm{w}^{0}= & \frac{1}{\mathrm{C}_{44}} \int \mathrm{f}(\tau) \mathrm{d} \tau=\frac{1}{\mathrm{C}_{44}} \int \frac{\mathrm{A}}{\tau^{2}(\tau-\beta) \mathrm{X}^{3 / 2}} \mathrm{~d} \tau \\
& =\frac{\mathrm{A}}{\mathrm{C}_{44} \beta} \int\left[-\frac{1}{\tau \beta}+\frac{1}{(\tau-\beta) \beta}-\frac{1}{\tau^{2}}\right] \frac{\mathrm{d} \tau}{\mathrm{X}^{3 / 2}}
\end{aligned}
$$

Known from eqn. $35, \mathrm{w}^{0}$ will be acquired with three terms. After separating denotation and using the essential formula ${ }^{26}$, it has:

$$
\begin{gathered}
\mathrm{w}_{1}{ }^{0}=\frac{1}{\mathrm{C}_{44}} \int \mathrm{f}_{1}(\tau) \mathrm{d} \tau=-\frac{\mathrm{A}}{\mathrm{C}_{44} \beta^{2}} \int \frac{1}{\tau \cdot \mathrm{X}^{3 / 2}} \mathrm{~d} \tau \\
=\frac{-2 \mathrm{~A}}{3 \beta^{2} \mathrm{C}_{44} \mathrm{~V}^{3}}\left[\frac{\mathrm{V}^{2}}{\tau \sqrt{\mathrm{X}}}-\frac{4 \sqrt{\mathrm{X}}}{\tau}+\frac{4 \tau}{\sqrt{\mathrm{X}}}\right]+\mathrm{C} \\
\mathrm{w}_{2}{ }^{0}=\frac{1}{\mathrm{C}_{44}} \int \mathrm{f}_{2}(\tau) \mathrm{d} \tau=\frac{\mathrm{A}}{\mathrm{C}_{44} \beta^{2}} \int \frac{1}{(\tau-\beta)} \frac{\mathrm{d} \tau}{\mathrm{X}^{3 / 2}} \\
\mathrm{w}_{3}{ }^{0}=\frac{1}{\mathrm{C}_{44}} \int \mathrm{f}_{1}(\tau) \mathrm{d} \tau=-\frac{\mathrm{A}}{\mathrm{C}_{44} \beta} \int \frac{1}{\tau^{2} \mathrm{X}^{3 / 2}} \mathrm{~d} \tau \\
=\frac{-2 \mathrm{~A}}{\beta \mathrm{C}_{44} \mathrm{~V}^{4}}\left[\frac{\tau}{\sqrt{\mathrm{X}}}-3 \frac{\sqrt{\mathrm{X}}}{\tau}-\frac{\mathrm{X}^{3 / 2}}{\tau^{3}}-\frac{1}{5} \frac{\mathrm{X}^{5 / 2}}{\tau^{5}}\right]+\mathrm{C}
\end{gathered}
$$

Denominator in eqn. 37 contains this term $(\tau-\beta) \mathrm{X}^{3 / 2}$, so the computation is incapable of using directly integral formulas, therefore integral format must translate into performable integral ${ }^{26}$.

By variable substitution: $\tau_{1}=\tau-\beta$, putting it into eqn. 34 , one can be obtained:

$$
\mathrm{X}=(\mathrm{V}-\tau) \tau=\mathrm{V} \beta-\beta^{2}+(\mathrm{V}-2 \beta) \tau_{1}-\tau_{1}^{2}
$$

The relative constants of eqn. 39 can be represented as follows: $\mathrm{a}_{1}=\mathrm{V} \beta-\beta^{2}, \mathrm{~b}_{1}=\mathrm{V}-2 \beta, \mathrm{c}=-1, \mathrm{~K}_{1}=4 \mathrm{a}_{1} \mathrm{c}-\mathrm{b}_{1}{ }^{2}$ $=-\mathrm{V}^{2}=\mathrm{K}$.

After integrating eqn. 37 by means of variable substitution, $\mathrm{w}_{2}{ }^{0}$ can be obtained as:

$$
\begin{aligned}
\mathrm{w}_{2}{ }^{0} & =\frac{\mathrm{A}}{\mathrm{C}_{44} \beta^{2}} \int \frac{\mathrm{d} \tau}{(\tau-\beta) \mathrm{X}^{3 / 2}}=\frac{\mathrm{A}}{\beta^{2} \mathrm{C}_{44}} \int \frac{\mathrm{d} \tau_{1}}{\tau_{1} \mathrm{X}^{3 / 2}} \\
& =\frac{\mathrm{A}}{\mathrm{a}_{1} \beta^{2} \mathrm{C}_{44}}\left[\frac{1}{\sqrt{\mathrm{X}}}+\int \frac{\mathrm{d} \tau_{1}}{\tau_{1} \sqrt{\mathrm{X}}}-\frac{\mathrm{b}_{1}}{2} \int \frac{\mathrm{d} \tau_{1}}{\mathrm{X}^{3 / 2}}\right]
\end{aligned}
$$

Known from eqn. 35: $\mathrm{w}^{0}(\tau)=\mathrm{w}_{1}{ }^{0}(\tau)+\mathrm{w}_{2}{ }^{0}(\tau)+\mathrm{w}_{3}{ }^{0}(\tau)$. The crack propagates along the $\mathrm{x}$-axis, consequently $\mathrm{w}^{0}(\tau)$ comprising eqns. 36,38 and 40 can be implemented in the definite integral operation, one takes constant $\mathrm{C}=0$.

Now putting eqn. 36 into 7, the divisional displacement $\mathrm{W}_{1}$ is:

$$
\begin{gathered}
\mathrm{w}_{1}=\int_{0}^{\mathrm{t}} \operatorname{Re~}_{1}^{0}(\tau) \mathrm{dt}=\operatorname{Re} \int_{\infty}^{\mathrm{x} / \mathrm{t}}-\frac{\mathrm{x}}{\tau^{2}} \mathrm{w}_{1}^{0}(\tau) \mathrm{d} \tau \\
=\frac{2 \mathrm{~A}}{3 \beta^{2} \mathrm{C}_{44} \mathrm{~V}^{3}} \operatorname{Re} \int_{\infty}^{\mathrm{x} / \mathrm{t}} \frac{\mathrm{x}}{\tau^{2}}\left[\frac{\mathrm{V}^{2}}{\tau \sqrt{\mathrm{X}}}-\frac{4 \sqrt{\mathrm{X}}}{\tau}+\frac{4 \tau}{\sqrt{\mathrm{X}}}\right] \mathrm{d} \tau
\end{gathered}
$$


Applying essential formulas in Literature ${ }^{26}$, the following representations are obtained.

$$
\begin{gathered}
\mathrm{S}_{1}=\int \frac{\mathrm{d} \tau}{\tau \sqrt{\mathrm{X}}}=-\frac{2 \sqrt{\mathrm{X}}}{\mathrm{b} \tau}=-\frac{2}{\mathrm{~b}} \sqrt{\frac{\mathrm{V}-\tau}{\tau}},(\text { for } \mathrm{a}=0) \\
\mathrm{S}_{2}=\int \frac{\mathrm{d} \tau}{\tau^{2} \sqrt{\mathrm{X}}}=\frac{-2}{\mathrm{~V}^{2}} \sqrt{\frac{\mathrm{V}-\tau}{\tau}}\left(1+\frac{\mathrm{V}-\tau}{3 \tau}\right) \\
=-\frac{2}{\mathrm{~V}^{2}} \frac{\sqrt{\mathrm{X}}}{\tau}\left(1+\frac{\mathrm{X}}{3 \tau^{2}}\right),(\text { for } \mathrm{a}=0) \\
=-\frac{2}{\mathrm{~V}^{3}} \sqrt{\frac{\mathrm{V}-\tau}{\tau}}\left[\frac{1}{5}\left(\sqrt{\frac{\mathrm{V}-\tau}{\tau}}\right)^{4}+\frac{2}{3}\left(\sqrt{\frac{\mathrm{V}-\tau}{\tau}}\right)^{2}+1\right] \\
=-\frac{2}{\mathrm{~V}^{3}} \frac{\sqrt{\mathrm{X}}}{\tau}\left(\frac{1}{5} \cdot \frac{\mathrm{X}^{2}}{\tau^{4}}+\frac{2}{3} \frac{\mathrm{X}}{\tau^{2}}+1\right),(\text { for } \mathrm{a}=0)
\end{gathered}
$$

Eqns. 42, 43 and 44 are deduced by this relationship: $\tau=\mathrm{V} \sin ^{2} \theta$.

After putting eqns. 42, 43 and 44 into 41, the divisional displacement $\mathrm{w}_{1}$ is obtained:

$$
\begin{gathered}
\mathrm{w}_{1}=\frac{2 \mathrm{Ax}}{3 \beta^{2} \mathrm{C}_{44} \mathrm{~V}^{3}} \operatorname{Re}\left[-\frac{2}{\mathrm{~V}} \frac{\sqrt{\mathrm{X}}}{\tau}\left(\frac{1}{5} \cdot \frac{\mathrm{X}^{2}}{\tau^{4}}+\frac{2}{3} \frac{\mathrm{X}}{\tau^{2}}+1\right)\right. \\
\left.+\frac{2 \sqrt{\mathrm{X}}}{\tau^{2}}+\mathrm{b} \cdot \frac{2}{\mathrm{~V}^{2}} \frac{\sqrt{\mathrm{X}}}{\tau}\left(1+\frac{1}{3} \cdot \frac{\mathrm{X}}{\tau^{2}}\right)-\frac{4 \sqrt{\mathrm{X}}}{\mathrm{b} \tau}-\frac{8 \sqrt{\mathrm{X}}}{\mathrm{b} \tau}\right]\left.\right|_{\infty} ^{\mathrm{x} / \mathrm{t}} \\
=\frac{2 \mathrm{~A}}{3 \beta^{2} \mathrm{C}_{44} \mathrm{~V}^{3}}\left\{\left[-\frac{2}{5 \mathrm{~V}} \cdot\left(\frac{\mathrm{Vt}-\mathrm{x}}{\mathrm{x}}\right)^{2}-\frac{2}{3 \mathrm{~V}} \cdot \frac{\mathrm{Vt}-\mathrm{x}}{\mathrm{x}}-\frac{12}{\mathrm{~b}}\right]\right. \\
\left.\sqrt{(\mathrm{Vt}-\mathrm{x}) \mathrm{x}}+2 \mathrm{t} \sqrt{\frac{\mathrm{Vt}-\mathrm{x}}{\mathrm{x}}}\right\}, 0<\mathrm{x}<\mathrm{V}_{\mathrm{t}}
\end{gathered}
$$

Then replacing eqn. 38 into 7 , the separated displacement $\mathrm{W}_{2}$ is:

$$
\begin{gathered}
\mathrm{w}_{2}=\int_{0}^{\mathrm{t}} \operatorname{Re~}_{2}{ }^{0}(\tau) \mathrm{dt}-\frac{\mathrm{Ax}}{\mathrm{C}_{44} \mathrm{a}_{1} \beta^{2}} \operatorname{Re} \int_{\infty}^{\mathrm{x} / \mathrm{t}} \frac{1}{\tau^{2}}\left[\frac{\mathrm{K}-\mathrm{b}_{1}^{2}-2 \mathrm{~b}_{1} \beta}{\mathrm{K} \sqrt{\mathrm{X}}}\right. \\
\left.-\frac{1}{\sqrt{\mathrm{a}_{1}}} \ln \left|\frac{\sqrt{\mathrm{X}}+\sqrt{\mathrm{a}_{1}}}{\tau-\beta}+\frac{\mathrm{b}_{1}}{2 \sqrt{\mathrm{a}_{1}}}\right|+\frac{2 \mathrm{~b}_{1} \tau}{\mathrm{K} \sqrt{\mathrm{X}}}\right] \mathrm{d} \tau
\end{gathered}
$$

The integral of the second term of eqn. 46 without coefficient can be rewritten as follows:

$$
\begin{aligned}
& \int-\frac{1}{\tau^{2} \sqrt{\mathrm{a}_{1}}} \ln \left|\frac{\sqrt{\mathrm{X}}+\sqrt{\mathrm{a}_{1}}}{\tau-\beta}+\frac{\mathrm{b}_{1}}{2 \sqrt{\mathrm{a}_{1}}}\right| \mathrm{d} \tau \\
& =\frac{1}{\sqrt{\mathrm{a}_{1}}} \int \ln \left|\frac{\sqrt{\mathrm{X}}+\sqrt{\mathrm{a}_{1}}}{\tau-\beta}+\frac{\mathrm{b}_{1}}{2 \sqrt{\mathrm{a}_{1}}}\right| \mathrm{d}\left(\frac{1}{\tau}\right)
\end{aligned}
$$

$$
\begin{gathered}
=\frac{1}{\tau \sqrt{\mathrm{a}_{1}}} \ln \left|\frac{\sqrt{\mathrm{X}}+\sqrt{\mathrm{a}_{1}}}{\tau-\beta}+\frac{\mathrm{b}_{1}}{2 \sqrt{\mathrm{a}_{1}}}\right| \\
+\frac{1}{\beta}\left(\frac{2 \sqrt{\mathrm{X}}}{\mathrm{b} \tau}+\frac{1}{\sqrt{\mathrm{a}_{1}}} \ln \left|\frac{\sqrt{\mathrm{a}_{1}}-\sqrt{\mathrm{X}}}{\tau-\beta}+\frac{\mathrm{b}_{1}}{2 \sqrt{\mathrm{a}_{1}}}\right|\right)
\end{gathered}
$$

Then inserting eqns. 47, 42 and 43 into 46, the zonal displacement $\mathrm{w}_{2}$ is as follows:

$$
\begin{aligned}
& \mathrm{w}_{2}=\frac{\mathrm{A}}{\mathrm{C}_{44} \mathrm{a}_{1} \beta^{2}}\left\{\frac{\mathrm{K}-\mathrm{b}_{1}^{2}-2 \mathrm{~b}_{1} \beta}{\mathrm{K}} \cdot \frac{2}{3 \mathrm{~V}^{2}} \sqrt{\frac{\mathrm{Vt}-\mathrm{x}}{\mathrm{x}}}(2 \mathrm{x}+\mathrm{Vt})\right. \\
& -\frac{2 \sqrt{(\mathrm{Vt}-\mathrm{x}) \mathrm{x}}}{\mathrm{b}}\left(-\frac{2 \mathrm{~b}_{1}}{\mathrm{~K}}+\frac{1}{\beta}\right) \\
& -\frac{\mathrm{t}}{\sqrt{\mathrm{a}_{1}}} \ln \left|\frac{\mathrm{t} \sqrt{\mathrm{a}_{1}}+\sqrt{(\mathrm{Vt}-\mathrm{x}) \mathrm{x}}}{\mathrm{x}-\beta \mathrm{t}}+\frac{\mathrm{b}_{1}}{2 \sqrt{\mathrm{a}_{1}}}\right| \\
& \left.-\frac{\mathrm{x}}{\beta \sqrt{\mathrm{a}_{1}}} \ln \left|\frac{\mathrm{t} \sqrt{\mathrm{a}_{1}}-\sqrt{(\mathrm{Vt}-\mathrm{x}) \mathrm{x}}}{\mathrm{x}-\beta \mathrm{t}}+\frac{\mathrm{b}_{1}}{2 \sqrt{\mathrm{a}_{1}}}\right|\right\}, 0<\mathrm{x}<\mathrm{V}_{\mathrm{t}} \text { (48) }
\end{aligned}
$$

Putting eqn. 38 into 7 , the divisional displacement $\mathrm{w}_{3}$ is:

$$
\begin{gathered}
\mathrm{w}_{3}=\operatorname{Re} \int_{\infty}^{\mathrm{x} / \mathrm{t}}-\frac{\mathrm{x}}{\tau^{2}} \mathrm{w}_{3}{ }^{0}(\tau) \mathrm{d} \tau \\
=\frac{2 \mathrm{Ax}}{\beta \mathrm{C}_{44} \mathrm{~V}^{4}} \operatorname{Re} \int_{\infty}^{\mathrm{x} / \mathrm{t}}\left[\frac{1}{\tau \sqrt{\mathrm{X}}}-\frac{3 \sqrt{\mathrm{X}}}{\tau^{3}}-\frac{\mathrm{X}^{3 / 2}}{\tau^{5}}-\frac{1}{5} \frac{\mathrm{X}^{5 / 2}}{\tau^{7}}\right] \mathrm{d} \tau
\end{gathered}
$$

After substituting eqns. 42, 43 and 44 into 49, this representation $\mathrm{w}_{3}$ is acquired:

$$
\begin{gathered}
\mathrm{w}_{3}=\frac{4 \mathrm{~A}}{\beta \mathrm{C}_{44} \mathrm{~V}^{4}}\left[\mathrm{t}\left(\frac{1}{\mathrm{~V}}-\frac{41}{75}\right) \sqrt{\frac{\mathrm{Vt}-\mathrm{x}}{\mathrm{x}}}-\frac{112}{75 \mathrm{~V}} \sqrt{(\mathrm{Vt}-\mathrm{x}) \mathrm{x}}\right. \\
\left.+\frac{6 \mathrm{Vt}^{2}}{25 \mathrm{x}^{2}} \sqrt{(\mathrm{Vt}-\mathrm{x}) \mathrm{x}}-\frac{1}{5 \mathrm{~V}} \arcsin \sqrt{\frac{\mathrm{x}}{\mathrm{Vt}}}\right], 0<\mathrm{x}<\mathrm{V}_{\mathrm{t}}
\end{gathered}
$$

The displacement is the summation of subdistrict displacement: $\mathrm{w}=\mathrm{w}_{1}+\mathrm{w}_{2}+\mathrm{w}_{3}$. After the addition among eqns. 45, 48 and 50, the displacement $\mathrm{w}$ is obtained as follows:

$$
\begin{aligned}
& \mathrm{w}=\frac{\mathrm{A}}{\mathrm{C}_{44} \beta}\left\{\frac{-2}{3 \beta \mathrm{V}^{3}}\left[\frac{1}{5 \mathrm{~V}} \cdot\left(\frac{\mathrm{Vt}-\mathrm{x}}{\mathrm{x}}\right)^{2}+\frac{1}{3 \mathrm{~V}} \cdot \frac{\mathrm{Vt}-\mathrm{x}}{\mathrm{x}}+\frac{6}{\mathrm{~b}}\right]\right. \\
& \left.-\frac{2}{\mathrm{~b} \beta \mathrm{a}_{1}}\left(\frac{1}{\beta}-\frac{2 \mathrm{~b}_{1}}{\mathrm{~K}}\right)+\frac{24 \mathrm{t}^{2}}{25 \mathrm{~V}^{3} \mathrm{x}^{2}}-\frac{448}{75 \mathrm{~V}^{5}}\right\} \sqrt{(\mathrm{Vt}-\mathrm{x}) \mathrm{x}}- \\
& -\frac{\mathrm{A}}{\mathrm{C}_{44} \beta^{2} \mathrm{a}_{1}{ }^{3 / 2}}\left[\mathrm{t} \ln \left|\frac{\mathrm{t} \sqrt{\mathrm{a}_{1}}+\sqrt{(\mathrm{Vt}-\mathrm{x}) \mathrm{x}}}{\mathrm{x}-\beta \mathrm{t}}+\frac{\mathrm{b}_{1}}{2 \sqrt{\mathrm{a}_{1}}}\right|\right. \\
& +\frac{\mathrm{x}}{\beta} \ln \mid \frac{\mathrm{t} \sqrt{\mathrm{a}_{1}}-\sqrt{(\mathrm{Vt}-\mathrm{x}) \mathrm{x}}}{\mathrm{x}-\beta \mathrm{t}}+\frac{\mathrm{b}_{1}}{\left.2 \sqrt{\mathrm{a}_{1}} \mid\right]+\frac{2 \mathrm{~A}}{3 \mathrm{~V}^{2} \mathrm{C}_{44} \beta}\left\{\frac{2 \mathrm{t}}{\mathrm{V} \beta}\right.}
\end{aligned}
$$




$$
\begin{gathered}
\left.+\frac{2 \mathrm{~A}}{3 \mathrm{~V}^{2} \mathrm{C}_{44} \beta}\right\}\left\{\frac{2 \mathrm{t}}{\mathrm{V} \beta}+\frac{1}{\beta} \cdot \frac{\mathrm{K}-\mathrm{b}_{1}^{2}-2 \mathrm{~b}_{1} \beta}{\mathrm{a}_{1} \mathrm{~K}}(2 \mathrm{x}+\mathrm{Vt})\right. \\
\left.+\frac{6 \mathrm{t}}{\mathrm{V}^{2}}\left(\frac{1}{\mathrm{~V}}-\frac{41}{75}\right)\right\} \sqrt{\frac{\mathrm{Vt}-\mathrm{x}}{\mathrm{x}}}, 0<\mathrm{x}<\mathrm{V}_{\mathrm{t}}
\end{gathered}
$$

where: $\mathrm{a}=0, \mathrm{~b}=\mathrm{V}, \mathrm{c}=-1, \mathrm{~K}=4 \mathrm{ac}-\mathrm{b}^{2}=-\mathrm{V}^{2}, \mathrm{a}_{1}=\mathrm{V} \beta-\beta^{2}$, $\mathrm{b}_{1}=\mathrm{V}-2 \beta, \mathrm{c}=-1, \mathrm{~K}_{1}=4 \mathrm{a}_{1} \mathrm{c}-\mathrm{b}_{1}^{2}=-\mathrm{V}^{2}=\mathrm{K}$.

Changeable law of dynamic stress intensity factor: Analytical solutions need transforming into numerical solutions according to the factual situation of concrete problems, therefore variable law of dynamic stress intensity factor can be displayed effectually. The corresponding parameters are put into eqns. 23 and 32 to readily plot $\mathrm{K}_{3}(\mathrm{t})$ as a function of time $\mathrm{t}$, respectively. The following constants ${ }^{28,29}$ postulated are as follows:

$$
\begin{aligned}
& \mathrm{C}_{44}=8 \mathrm{GPa}, \quad \mathrm{C}_{55}=16 \mathrm{GPa}, \quad \rho=2.7 \times 9.8 \times 10^{3} \mathrm{~N} \mathrm{~m}^{-3} \\
& \mathrm{~V}=300 \mathrm{~ms}^{-1}, \mathrm{P}=200 \mathrm{~N}, \beta=180 \mathrm{~ms}^{-1}
\end{aligned}
$$

Known from eqn. 23, dynamic stress intensity factor $\mathrm{K}_{3}(\mathrm{t})$ reduces laggardly and trends to a constant finally and has apparent singularity with the prolong of time, as shown in Fig. 2. The relative numerical value relationship is depicted in Table-1. This variable trend is similar to the outcome in literatures ${ }^{29-31}$, consequently the result obtained is approved to be correct. In the light of eqn. 32, dynamic stress intensity factor $\mathrm{K}_{3}(\mathrm{t})$ gradually increase from zero, but its increasing current is slow and even reach or exceed fracture toughness of this material, therefore, structural destruction will occur, as described in Fig. 3. $\mathrm{T}$ Such an uptrend is homogeneous to the result in literatures $^{29,32-35}$, therefore, it is also right. The correlative numerical value relation is indicated in Table-2.

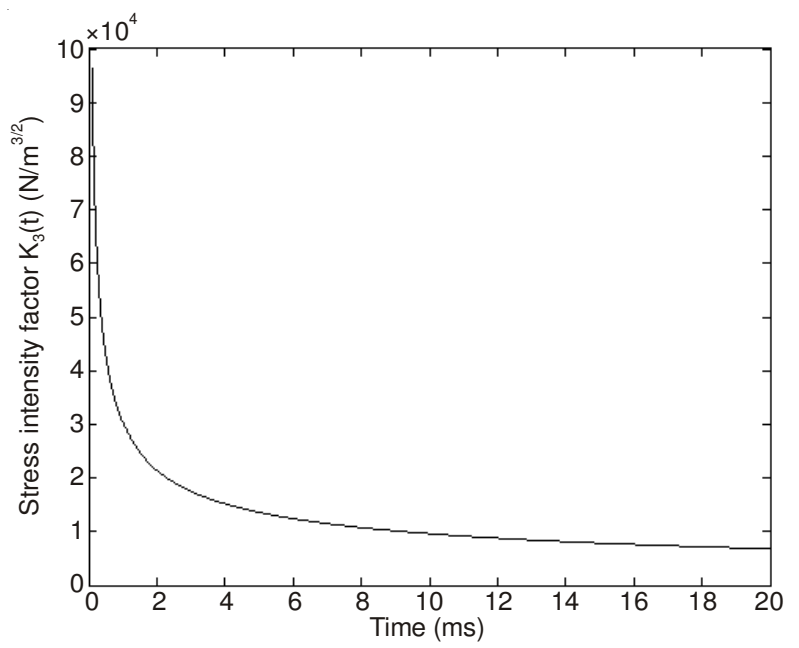

Fig. 2. Dynamic stress intensity factors $\mathrm{K}_{3}(\mathrm{t})$ versus time $\mathrm{t}$

\section{TABLE-1}

CORRELATIVE NUMERICAL VALUES BETWEEN DYNAMIC STRESS INTENSITY FACTOR $\mathrm{K}_{3}(\mathrm{t})$ versus TIME $\mathrm{t}$

\begin{tabular}{cccccc}
\hline $\mathrm{t}(\mathrm{ms})$ & 2 & 4 & 6 & 8 & 10 \\
\hline $\mathrm{K}_{3}(\mathrm{t}) \times 10^{4} / \mathrm{N} \cdot \mathrm{m}^{-3 / 2}$ & 2.1535 & 1.5228 & 1.2433 & 1.0768 & 0.9631 \\
\hline $\mathrm{t}(\mathrm{ms})$ & 12 & 14 & 16 & 18 & 20 \\
\hline $\mathrm{K}_{3}(\mathrm{t}) \times 10^{4} / \mathrm{N} \cdot \mathrm{m}^{-3 / 2}$ & 0.8792 & 0.8140 & 0.7614 & 0.7178 & 0.6810 \\
\hline
\end{tabular}

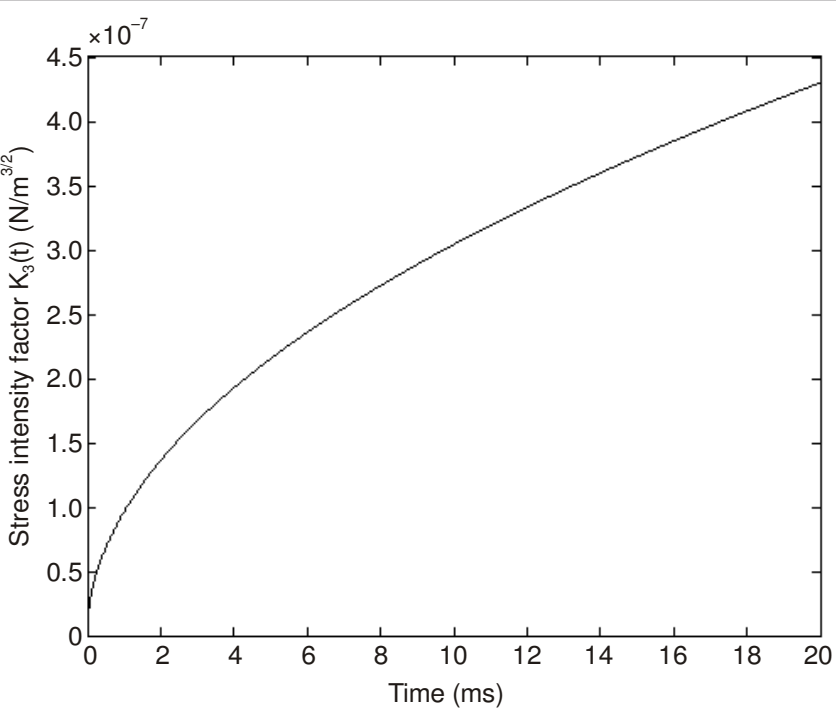

Fig. 3. Dynamic stress intensity factor $\mathrm{K}_{3}(\mathrm{t})$ versus time $t$

TABLE-2

CORRELATIVE NUMERICAL VALUES BETWEEN DYNAMIC STRESS INTENSITY FACTOR $\mathrm{K}_{3}(\mathrm{t})$ VERSUS TIME $\mathrm{t}$

\begin{tabular}{cccccc}
\hline $\mathrm{t}(\mathrm{ms})$ & 2 & 4 & 6 & 8 & 10 \\
\hline $\mathrm{K}_{3}(\mathrm{t}) \times 10^{-7} / \mathrm{N} \cdot \mathrm{m}^{-3 / 2}$ & 1.3591 & 1.9219 & 2.3538 & 2.7183 & 3.0388 \\
\hline $\mathrm{t}(\mathrm{ms})$ & 12 & 14 & 16 & 18 & 20 \\
\hline $\mathrm{K}_{3}(\mathrm{t}) \times 10^{-5} / \mathrm{N} \cdot \mathrm{m}^{-3 / 2}$ & 3.3288 & 3.5955 & 3.8438 & 4.0771 & 4.2975 \\
\hline
\end{tabular}

\section{Conclusion}

Applying the relative expression: $\mathrm{f}(\mathrm{x}, \mathrm{y}, \mathrm{t})=\mathrm{t}^{\mathrm{n}} \mathrm{f}(\mathrm{x} / \mathrm{t}, \mathrm{y} / \mathrm{t})$, just $\mathrm{n}$ is an integer number; and then the problem investigated will be facilely transformed into homogeneous functions of zeroth dimension, i.e., homogeneous functions. All satisfying this function relationship are solved by eqns. 6-8 according to the modality of homogeneous functions corresponding to variable $\tau$. This approach is utilized not only in elastodynamics $^{4,6,7,14-16,20,21,36,37}$, but also in elastostatics ${ }^{18,24,25,38,39}$, so much as in the else region ${ }^{39,40}$.

Introducing the measures of the self-similar functions is capable of gaining analytical solution of active propagation problems concerning mode III semi-infinite crack surfaces subjected to motive increasing loads $\mathrm{Px}^{2} / \mathrm{t}^{2}$ and $\mathrm{Pt}^{3} / \mathrm{x}^{2}$, respectively. This is referred to as the analogous class of dynamic problem of the elasticity theory. The method of solution is based exclusively on techniques of analytical-function theory and is straightforward and concise. By making some observations regarding the solution of the mixed boundary-value problem, this has fairly reduced the amount of the calculative work needed to settle such a crack extension problem.

\section{REFERENCES}

1. A.C. Erigen and E.S. Suhubi, Elastodynamics, Linear Theory, Academic Press. New York, San Francisco, London, Vol. 2 (1975).

2. G.C. Sih, Mechanics of Fracture 1: Methods of Analysis and Solutions of Crack Problems, Noordhoff, Leyden (1977).

3. F. Erdogan, Crack Propagation Theories: Fracture II, Academic Press, New York, pp. 497-509 (1968).

4. G.P. Cherepanov, Mechanics of Brittle Fracture, McGraw Hill International Book Company, New York, pp. $732-792$ (1979).

5. G.C. Sih, Int. J. Fract. Mechan., 4, 51 (1968).

6. B.V. Kostrov, J. Appl. Math. Mech., 28, 1077 (1964).

7. L.B. Freund, Dynamic Fracture Mechanics, Cambridge University Press, Cambridge, UK (1990). 
8. G.C. Sih and B. MacDonald, Eng. Fract. Mech., 6, 361 (1974).

9. G.C. Sih, Handbook of Stress Intensity Factors, Inst. Frac. Solid. Mech. Lehigh University, Bethlehem, PA (1973).

10. G.C. Sih, Mechanics of Fracture Initiation and Propagation, Kluwer Academic Publisher, Boston (1991).

11. Y.H. Wang, Y.K. Cheung and C.W. Woo, Eng. Fract. Mech., 42, 971 (1992).

12. G. Ravichandran and W. G. Knauss, Int. J. Fract., 39, 235 (1989).

13. Y.H. Wang, Eng. Fract. Mech., 42, 45 (1992).

14. L. Nian-chun, C. Jin and C. Yun-hong, Inst. Tech., 37, 1093 (2005) (in Chinese).

15. L. Nian-chun, C. Yun-hong and C. Jin, J. Appl. Mech., 21, 156 (2004) (in Chinese).

16. L. Nian-chun, C. Yun-hong, T. Xiu-bo and C. Jin, Inst. Tech., 38, 1310 (2006) (in Chinese).

17. N.I. Muskhelishvili, Singular Integral Equations, Nauka, Moscow (1968).

18. N.I. Muskhelishvili, Some Fundamental Problems in the Mathematical Theory of Elasticity, Nauka, Moscow (1966)

19. C. Atkinson, Int. J. Eng. Sci., 13, 489 (1975).

20. C. Atkinson, Int. J. Eng. Sci., 3, 77 (1965).

21. R.F. Hoskins, Generalized functions, Ellis Horwood, pp. 19-125 (1979).

22. X.-S. Wang, Singular Functions and Their Applications in Mechanics, Scientific Press, Beijing, pp. 3-45 (1993) (in Chinese).

23. F.D. Gahov, Boundary-value problems, Fizmatgiz, Moscow, pp. 10-136 (1963).

24. G.C. Sih, Mechanics of Fracture 4. Elastodynamics Crack Problems, Noordhoff, Leyden, pp. 213-247 (1977).
25. R.P. Kanwal and D.L. Sharma, J. Elast., 6, 405 (1976).

26. Editorial Group of Mathematics Handbook, Mathematics Handbook, Advanced Education Press, Beijing, pp. 244-300 (2002) (in Chinese).

27. Teaching Office of Mathematics of Tongji University, Advanced Mathematics, Advanced Education Press, Beijing, Vol. 1, pp. 167-172 (1994) (in Chinese).

28. K.-C. Wu, Int. J. Fract., 106, 1 (2000).

29. N.- Lü, Y.- Cheng, X.- Li and J. Cheng, Appl. Math. Mech., 29, 1279 (2008).

30. J.F. Kalthoff, J. Beinert and S. Winkler, ASTM Spec. Tech. Publ., 627, 161 (1977).

31. A.S. Kobayashi, Dynamic Fracture Analysis by Dynamic Finite Element Method: Generation and Prediction Analyses, In: Nonlinear and Dynamic Fracture Mechanics, ASME, New York, NY: Amd., 35, pp. 19-36 (1979).

32. K. Ravi-Chandar and W.G. Knauss, Int. J. Fract., 25, 247 (1984).

33. K. Ravi-Chandar and W.G. Knauss, Int. J. Fract., 26, 65 (1984).

34. K. Ravi-Chandar and W.G. Knauss, Int. J. Fract., 26, 141 (1984).

35. K. Ravi-Chandar and W.G. Knauss, Int. J. Fract., 26, 189 (1984).

36. N.C. Lü, Y.H. Cheng, X.G. Li and J. Cheng, Fati. Frac. Eng. Mater. Stru., 33, 141 (2010). (J).

37. N.C. Lü, Y.H. Cheng, X.G. Li and J. Cheng, Compos. Interfaces, 17, 37 (2010).

38. N.I. Sneddon, Fourier Transform, McGraw-Hill, New York (1951).

39. N.I. Muskhelishvili, Some Basic Problems from the Mathematical Theory of Elasticity, P. Noordoff, Groningen-Holland (1953).

40. L.A. Galin, Contact Problems in Elasticity Theory, GITTL, Moscow (1953). 